\title{
MORTALITIES ASSOCIATED WITH SEPSIS, PARASITISM, AND DISSEMINATED ROUND CELL NEOPLASIA IN YELLOW-LIPPED SEA KRAITS (LATICAUDA COLUBRINA)
}

\author{
Sathya K. Chinnadurai, D.V.M., M.S., Danielle L. Brown, D.V.M., Arnaud Van Wettere, D.V.M., \\ M.S., Allison D. Tuttle, D.V.M., Dipl. A.C.Z.M., Michael H. Fatzinger, Keith E. Linder, D.V.M., \\ Ph.D., Dipl. A.C.V.P., and Craig A. Harms, D.V.M., Ph.D., Dipl. A.C.Z.M.
}

\begin{abstract}
This case series describes multiple mortalities associated with sepsis, neoplasia, and endoparasitism in yellow-lipped sea kraits (Laticauda colubrina) at an exhibit aquarium. Over a 2-yr period, the facility kept $42 \mathrm{~L}$. colubrina, of which 38 died and 19 were suitable for necropsy and histopathology. The common clinical syndrome seen in these animals consisted of partial to compete anorexia, increased time spent "hauled-out" on land, intermittent regurgitation, chronic lethargy, and weight loss. Few animals died without premonitory signs. Nutritional support and treatment for presumptive parasitism and sepsis were unsuccessful. The mortality seen in this collection of sea kraits could be placed into three groups; one group of animals $(n=9)$ died of sepsis secondary to necrotizing enteritis or pneumonia; one group $(n=6)$ remained apparently healthy for over $1 \mathrm{yr}$ and then died with multifocal granulomas and sepsis; and the last group $(n=3)$ died as a result of multicentric lymphoid neoplasia with secondary sepsis. The unifying factor in the majority of these cases is the presence of septicemia as the proximate cause of death. Based on the clinical picture, it is presumed that an immunosuppressive event, such as transport, captivity stress, or possible concurrent viral infection, resulted in a septic event and death.

Key words: Laticauda colubrina, neoplasia, parasite, sepsis, yellow-lipped sea krait.
\end{abstract}

\section{INTRODUCTION}

Sea snakes represent over 70 species in 26 genera. Sea kraits are snakes belonging to the Laticau$d a$ genus and include three marine and one freshwater species, all of which are native to southeast Asia. ${ }^{13}$ Though extensive research has been conducted on the physiology and natural history of sea snakes, little has been documented in the literature regarding diseases in the wild or care in captivity., 7 Discussion of sea snake captive husbandry is limited to reports of few individuals and focuses on the difficulty of maintaining the animals in captivity for longer than 1-2 mo, with isolated reports of individuals living 3-5 yr. ${ }^{12,20}$ Mortalities described in these reports are often attributed to inanition from poor feeding, though no necropsy or histopathology data were presented. A comprehensive

From the Departments of Clinical Sciences (Chinnadurai, Tuttle, Harms) and Population Health and Pathobiology (Brown, Van Wettere, Linder), North Carolina State University, College of Veterinary Medicine, 4700 Hillsborough Street, Raleigh, North Carolina 27606, USA; North Carolina State University, Center for Marine Sciences and Technology, 303 College Circle, Morehead City, North Carolina 28557, USA (Harms); and North Carolina Aquarium at Fort Fisher, 900 Loggerhead Road, Kure Beach, North Carolina 28449, USA (Fatzinger). Correspondence should be directed to Dr. Harms (craigharms@ncsu.edu). bibliography of sea snake literature does not include any disease citations. ${ }^{4}$ Previous reports of wild sea snake morbidity are limited to descriptions of parasitism. ${ }^{16,19}$ An isolated report of lymphoid leukemia in a captive Laticauda colubrina describes a mortality without premonitory signs. ${ }^{22}$

This case series describes multiple mortalities associated with sepsis, neoplasia, and endoparasitism in L. colubrina at the North Carolina Aquarium at Fort Fisher (NCAFF) (North Carolina, USA). To date, this report represents the first detailed description of sea snake morbidity, mortality, and pathology related to sea snakes maintained in captivity.

\section{CASE REPORTS}

From May 2005 through February 2007, the facility received and maintained adult yellow-lipped sea kraits (L. colubrina), which were wild-collected in Bali, Indonesia. The animals were housed with Erabu sea snakes (Laticauda semifasciata), five of which were wild-collected in Japan and one of which was obtained from another U.S. institution. During the period of this report, the facility kept 42 L. colubrina, of which 38 died. The animals ranged from 288-888 g. Many of the animals died in their enclosures overnight, making prompt necropsy and formalin fixation impossible. All animals not grossly autolyzed when recovered $(n=19 ; 13$ males and 6 females) were submitted for necropsy and histopathology. 
Table 1. Summary of histopathologic findings in $\mathrm{La}$ ticauda colubrina $(n=19)$. Some animals were affected by more than one finding.

\begin{tabular}{lc}
\hline \multicolumn{1}{c}{ Histopathologic finding } & No. affected \\
\hline Multifocal necrotizing enteritis & 5 \\
Multifocal necrotizing pneumonia & 4 \\
Multifocal hepatic necrosis with intra- & \\
$\quad$ lesional bacteria & 11 \\
Disseminated granulomas & 6 \\
Disseminated round cell neoplasia & 3 \\
Endoparasitism & \\
$\quad$ Pulmonary nematodes & 4 \\
Pulmonary trematodes & 2 \\
$\quad$ Intestinal nematodes & 1 \\
Intestinal protozoa & 1 \\
Intravascular microfilaria & 5 \\
\hline
\end{tabular}

The first shipment of 19 snakes arrived in May 2005 and was placed in saltwater quarantine tanks with dry haul-out areas. Water temperature was maintained between $26.7-28.8^{\circ} \mathrm{C}\left(80-84^{\circ} \mathrm{F}\right)$, and water quality standards were similar to those in fish systems with salinity of 30-32 ppt. The L. colubrina were fed a diet of live American eels ( $A n-$ guilla rostrata) based on recommendations from other institutions and food preference in the wild. ${ }^{6,21}$

Within 2 wk of shipment, three animals developed severe stomatitis and one died. One of the remaining animals was treated unsuccessfully with enrofloxacin (Baytril, Bayer Animal Health, Shawnee, Kansas 66216, USA; $10 \mathrm{mg} / \mathrm{kg}$, diluted $1: 1$ in sterile water, administered subcutaneously [s.c.] every $48 \mathrm{hr}$ ). All three animals died within $4 \mathrm{wk}$ of shipment. Histopathology of one snake showed focal, severe heterophilic stomatitis and severe chronic heterophilic and histiocytic interstitial bronchopneumonia with a high load of filarid nematodes. Treatment aimed at controlling the filarid parasite load was started on the remaining snakes (levamisole, $10 \mathrm{mg} / \mathrm{kg}$, s.c., every $3 \mathrm{wk}$ for three treatments). Two more animals died by the end of the first month, and the surviving animals remained anorexic. Based on recommendations from other facilities, 6 of the 12 remaining animals were transferred to $122 \times 91 \times 46-\mathrm{cm}$ plastic snake cages with wet moss substrate and water dishes for feeding. After $1 \mathrm{mo}$ these semiterrestrial animals were still not eating and two of them died; the remaining snakes were returned to saltwater tanks. The smallest snakes were tube-fed pureed eels with minimal success. By August 2005, 11 animals from the original shipment had died and three were transferred to another institution.

In August 2005, a second shipment arrived con-

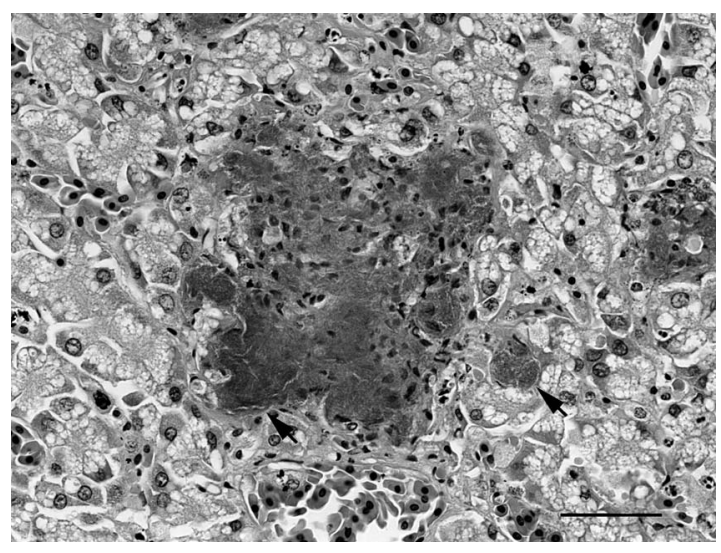

Figure 1. Liver, yellow-lipped sea krait (Laticauda colubrina). Focal area of necrosis in the hepatic parenchyma with intralesional bacteria (arrow). Hematoxylin and eosin $(\mathrm{H} \& \mathrm{E})$, bar $=50 \mu \mathrm{m}$.

taining 39 new animals, of which 16 were shipped to other institutions. In quarantine, hematology and serum chemistry were performed on four animals and were found to be unremarkable, except for the fact that hemogregarine parasites occupied red blood cells in all four snakes. Within $3 \mathrm{wk}$ of acquisition, multiple animals developed a common clinical syndrome consisting of partial to complete anorexia, increased time spent "hauled-out" on land, intermittent regurgitation with chronic lethargy, and weight loss. Treatment for presumptive parasitism and sepsis consisted of ceftazadime (Fortaz ${ }^{\circledR}$, GlaxoSmithKline, Research Triangle Park, North Carolina 27709, USA; 20 mg/kg, s.c., every 72 hr), metronidazole (Teva Pharmaceuticals USA, Kulpsville, Pennsylvania 19443, USA; 25 $\mathrm{mg} / \mathrm{kg}$, administered by mouth, every $72 \mathrm{hr}$ ), and levamisole (Levasole 13.65\%, Schering-Plough, Madison, New Jersey 07940, USA; 10 mg/kg, s.c., every $3 \mathrm{wk}$ ).

Over the subsequent 10 mo, 20 animals died; no abnormalities were noted on gross necropsy, and only six carcasses were of suitable condition for histopathology. Histopathology showed evidence of necrotizing enteritis in four of six snakes and necrotizing pneumonia in the remaining two snakes (Table 1). The necrotizing enteritis was characterized by accumulations of cellular debris, fibrin, and bacteria in the intestinal lumen in conjunction with mucosal ulceration and heterophil invasion into the underlying lamina propria and submucosa. Three animals demonstrated moderate to severe multifocal hepatocellular necrosis with intralesional bacteria (Fig. 1). Additionally, fibrin thrombi were observed in a moderate number of sinusoids and small 


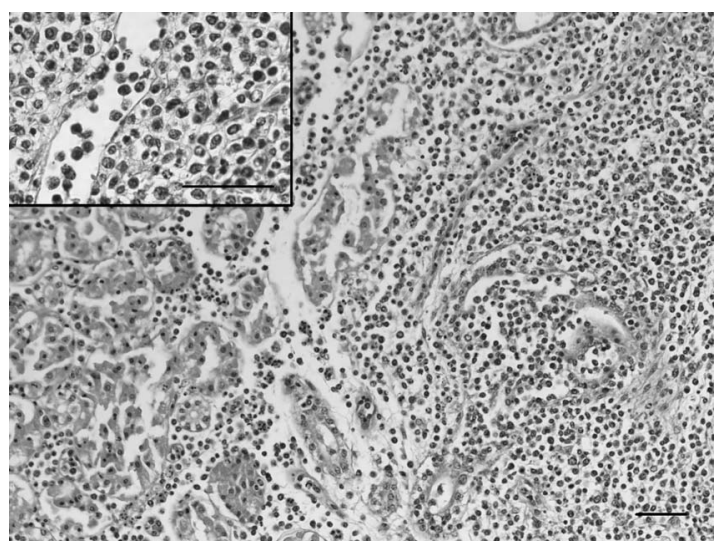

Figure 2. Kidney, yellow-lipped sea krait (Laticauda colubrina). Renal parenchyma infiltrated and effaced by a monomorphic population of neoplastic round cells. Hematoxylin and eosin (H\&E), bar $=50 \mu \mathrm{m}$. Insert: H\&E, bar $=50 \mu \mathrm{m}$.

vessels. Those animals that did not show histologic lesions of necrotizing enteritis had gastrointestinal tracts that were too autolyzed to interpret and may have had concurrent enteritis and pneumonia.

Six snakes died and were necropsied between December 2006 and January 2007; all had scattered granulomas throughout the lung, heart, kidney, spleen, and gastrointestinal tract. The granulomas were characterized by central eosinophilic cellular and karyorrhectic debris surrounded by a ring of epithelioid macrophages and a thin band of peripheral fibroblasts. Microscopic examination of the granulomas was negative for acid-fast and Grampositive bacteria and revealed no parasites. Multifocal hepatic necrosis with aggregates of Gramnegative bacilli, similar to that seen in previous cases involving sepsis, was found in four of six snakes.

One female and two male L. colubrina died in August 2006 and February 2007, respectively, with evidence of disseminated round cell neoplasia and concurrent sepsis. The female had a $3 \times 1 \times 1-$ $\mathrm{cm}$, pale, firm, multinodular subcutaneous mass on the dorsum, at the midbody. On histopathology, the animal had disseminated round cell neoplasia within the subcutaneous mass, lung, liver, spleen, gonad, and kidneys (Fig. 2). Neoplastic cells were round, with a moderate amount of eosinophilic to amphophilic cytoplasm and round central nuclei. There were multifocal aggregates of bacteria in the pulmonary capillaries and expansion of the pulmonary interstitium with neoplastic round cells. Similar bacterial aggregates were seen in all organs examined. Both male snakes had multifocal 1-2$\mathrm{mm}$, round, white areas on the surface of the liver, extending into the parenchyma, and one had a 1$\mathrm{cm}$ subcutaneous abscess. Neoplastic infiltration was seen in the heart, lung, liver, intestines, and skin. Invasion of the kidney with neoplastic cells was associated with expansion of the interstitium and obliteration of renal tubules. A blood smear made from a postmortem cardiocentesis demonstrated 80-90\% large immature lymphoid cells and an estimated white cell count of 60,000-75,000 cells/ $\mu 1$, both of which are consistent with a lymphoid leukemia. Transmission electron microscopy failed to detect viral particles in the formalin-fixed samples of the liver and kidney of one snake. Aerobic and anaerobic cultures were collected from multiple organs in both male snakes (North Carolina State University, College of Veterinary Medicine, Raleigh, North Carolina 27606, USA). Moderate growth of Citrobacter freundii, Aeromonas hydrophila, and Klebsiella pneumonia was found in the liver. Light growth of Escherichia coli, Enterococcus faecalis, and Provedencia rettgeri was isolated from the proximal gastrointestinal tract. The subcutaneous abscess produced heavy growth of $A$. hydrophila, Shewanella putrefaciens, and Edwardsiella tarda. Resistance to enrofloxacin was found in $K$. pneumonia, and resistance to ceftazadime was detected in A. hydrophila. Cultures of kidney, lung, heart, and colon from one of the snakes also yielded Salmonella arizonae subspecies 4, O group (cell wall antigen) 44, and $\mathrm{H}$ group (flagella antigen) $\mathrm{Z} 4$, Z32 (National Veterinary Services Laboratory, Ames, Iowa 50010, USA).

In addition to evidence of septicemia, animals from this collection carried varying loads of parasites in the lungs, intestine, and blood vessels. The parasites included protozoa, microfilaria, and trematodes in the lung and nematodes and protozoa in the intestine. The most common parasites were intravascular nematode microfilaria, found in five animals (Fig. 3). There was no consistent trend in the type and distribution of parasites, and there was no evidence of inflammation or morbidity associated with parasitism.

Elective necropsies were performed on four American eels from the aquarium food stock to assess the potential for food animals contributing to disease of the sea snakes. Gross and histopathologic findings included several small granulomas containing myxozoan spores, consistent with Myxidium giardi, and necrotic debris. One eel had a single Anguillicola crassus nematode in the swim bladder. The nematode and the myxozoan granulomas were considered incidental findings, as these parasites were not found in the dead sea kraits and are common in American eels. ${ }^{15,17}$ Based on poor success, 


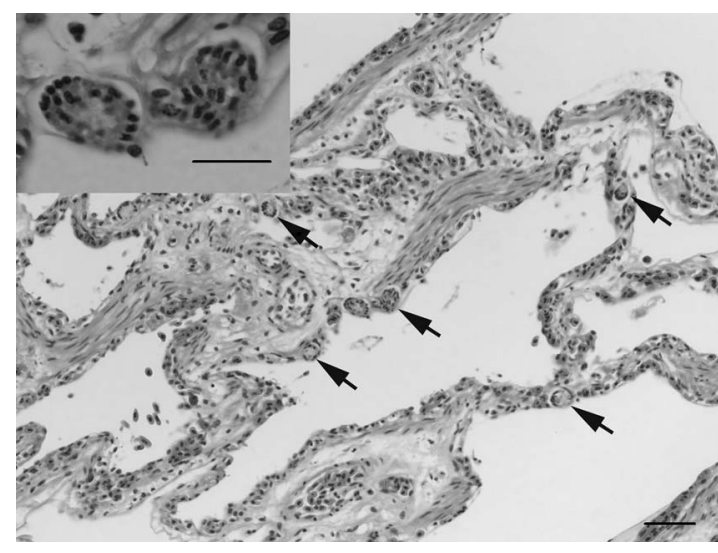

Figure 3. Lung, yellow-lipped sea krait (Laticauda colubrina). Numerous intravascular nematode microfilaria in the pulmonary faveolar capillaries (arrow). Hematoxylin and eosin (H\&E), bar $=50 \mu \mathrm{m}$. Insert: H\&E, bar $=$ $20 \mu \mathrm{m}$.

despite a thorough diagnostic and treatment regimen, and as a result of difficulty in acquiring sufficient commercially available antivenin for personnel safety, the facility elected to transfer the remaining snakes to another institution.

\section{DISCUSSION}

The mortalities seen in this collection of $L$. colubrina can be classified into three groups: one group of animals died of sepsis secondary to a necrotizing enteritis or pneumonia; one group remained apparently healthy for over $1 \mathrm{yr}$ and then died with multiorgan granulomas and sepsis; and the last group died as a result of multicentric lymphoid neoplasia with secondary sepsis. The unifying factor in the majority of these cases is the histologic evidence of septicemia as the proximate cause of death.

In the animals necropsied, liver, lung, and intestine were the most commonly affected tissues. Eleven of 19 animals demonstrated severe hepatic necrosis with fibrin microthrombi within the sinusoids, which was interpreted as a sign of sepsis. Six animals had multiorgan granulomas in conjunction with hepatic necrosis. Well-formed discrete granulomas can represent the end stage of histiocytic or heterophilic granuloma formation in reptiles and may be associated with previous bacterial, fungal, or parasitic infection. ${ }^{14}$ Septicemia is a common disease syndrome in reptiles and is often linked to a presumed immunosuppressive event, such as stress of transport and captivity or concurrent viral infection. ${ }^{10}$

Three of the snake deaths (16\% of the L. colu- brina necropsied) involved disseminated round cell neoplasia, one of which was leukemic. Each of these snakes had abnormal populations of neoplastic lymphoid cells in various organs with concurrent sepsis. Lymphoid and hematopoietic neoplasias are the most common tumors reported in snakes. ${ }^{2} \mathrm{Sev}$ eral etiologies have been implicated for round cell neoplasia in reptiles, including retrovirus. , $^{2,3,5-11,18}$ In the three cases described here, viral-induced neoplasia was a potential cause of immunosuppression and subsequent sepsis, although transmission electron microscopy did not reveal viral particles in neoplastic tissues. Electron microscopy is a lowsensitivity test for diagnosing viral diseases, but it has been used successfully., ${ }^{3,8,11,18}$ Financial and logistical constraints prevented further investigation of viral etiologies through virus isolation, additional electron microscopy, or polymerase chain reactionbased diagnostics.

The L. colubrina were housed with six L. semifasciata, three of which died and were necropsied. Two individuals showed no evidence of sepsis and the third had severe dermatitis and sepsis. No $L$. semifasciata individuals had evidence of round cell neoplasia, despite exposure to affected $L$. colubri$n a$. Our findings are consistent with the single report of lymphoid leukemia in a L. colubrina, in which many yellow-bellied sea kraits (Pelamis platurus) exposed to the affected individual died and none of the $L$. semifasciata were affected. ${ }^{22}$ One $L$. semifasciata, which was in contact with the animals described in the initial report, was transferred to the NCAFF. If an infectious etiology, such as a retrovirus, was responsible for these cases, then L. semifasciata may demonstrate resistance and be a potential reservoir species.

Eight animals in this group had moderate to severe endoparasitism. Organisms were found in the lung, gastrointestinal tract, and vasculature. Though parasite numbers were considered high in some animals, there was no histologic evidence of inflammation associated with the parasites. Pulmonary mites and nematodes as well as intestinal nematodes and trematodes have been reported in wild sea snakes with minimal effect on health. ${ }^{16,19}$ Wild sea snakes are common paratenic hosts of intravascular filarid nematodes, including Angiostrongylus cantonensis. ${ }^{1}$ The snakes in this collection were never exposed to other reptiles in captivity, and the parasites found were likely present at the time of capture.

Sea snakes are considered difficult to maintain in captivity, often as a result of their unexplained mortality and refusal of food. ${ }^{7,12,20}$ For these reasons, sea snakes are uncommonly kept at U.S. institutions, 
and reports of husbandry recommendations and diseases are rare. ${ }^{13}$ With the limited body of information on sea snakes, diagnostics and treatments based on published information for other snake species were attempted. Though a unifying etiology has not been identified, common characteristics of these multiple mortalities were identified. Based on the clinical and epidemiologic picture, it is presumed that an immunosuppressive event, such as transport or confinement stress and/or concurrent viral infection, may have resulted in sepsis and death. In the wild, yellow-lipped sea kraits are known for their timidity and spend much of their time on land completely hidden. ${ }^{21}$ In a captive situation, which puts the animals in repeated human proximity, chronic stress can lead to the animal becoming immunocompromised and inanition may occur. This report is intended to supply veterinarians and aquarists with detailed information on the pathology seen in this collection of sea kraits and to serve as a basis for future care and treatment of these species.

\section{LITERATURE CITED}

1. Ash, L. R. 1968. The occurrence of Angiostrongylus cantonensis in frogs of New Caledonia with observations on paratenic hosts of metastrongyles. J. Parasitol. 54: 432436.

2. Catao-Dias, J. L., and D. K. Nichols. 1999. Neoplasia in snakes at the National Zoological Park, Washington, DC (1978-1997). J. Comp. Pathol. 120: 89-95.

3. Chandra, A. M., E. R. Jacobson, and R. J. Munn. 2001. Retroviral particles in neoplasms of Burmese pythons (Python molurus bivittatus). Vet. Pathol. 38: 561564.

4. Culotta, W., and G. Pickwell. 1993. The Venomous Sea Snakes: A Comprehensive Bibliography. Krieger Publishing Company, Malabar, Florida. Pp. 432-436.

5. Finnie, E. P. 1972. Lymphoid leucosis in an Indian python (Python molurus). J. Pathol. 107: 295-297.

6. Heatwole, H. 1999. Sea Snakes. Krieger Publishing Company, Malabar, Florida. Pp. 46-52, 108-126.

7. Herre, A. W., and D. S. Rabor. 1949. Notes on the Philippine sea snakes of the genus Laticauda. Copeia 4: 282-284.

8. Ippen, R., Z. Mladenov, and A. Konstantinov. 1978. Leukosis with viral presence proven by means of an electron microscope in 2 boa constrictors. Schweiz. Arch. Tierheilkd. 120: 357-368.
9. Jacobson, E., M. B. Calderwood, T. W. French, W. Iverson, D. Page, and B. Raphael. 1981. Lymphosarcoma in an Eastern king snake and a rhinoceros viper. J. Am. Vet. Med. Assoc. 179: 1231-1235.

10. Jacobson, E. R. 2007. Viruses and viral diseases of reptiles. In: Jacobson, E. R. (eds.). Infectious Diseases and Pathology of Reptiles. CRC Press, Boca Raton, Florida. Pp. 409-412.

11. Jacobson, E. R., J. C. Seely, and M. N. Novilla. 1980. Lymphosarcoma associated with virus-like intranuclear inclusions in a California king snake (Colubridae: Lampropeltis). J. Natl. Cancer Inst. 65: 577-583.

12. Klemmer, K. 1969. Observations on the sea-snake (Laticauda colubrina) in captivity. Int. Zoo Yearb. 9: 7229-7231.

13. Mehrtens, J. 1987. Living Snakes of the World. Sterling Publishing, New York, New York. Pp. 282-284.

14. Montali, R. J. 1988. Comparative pathology of inflammation in the higher vertebrates (reptiles, birds and mammals). J. Comp. Pathol. 99: 1-26.

15. Moser, M. L., W. S. Patrick, and J. U. Crutchfield. 2001. Infection of American eels, Anguilla rostrata, by an introduced nematode Parasite, Anguillicola crassus, in North Carolina. Copeia 3: 848-853.

16. Nadchatram, M. 2006. A review of endoparasitic acarines of Malaysia with special reference to novel endoparasitism of mites in amphibious sea snakes and supplementary notes on ecology of chiggers. Trop. Biomed. 23: $1-22$.

17. Newman, M. W. 1977. Cutaneous Myxosporidiosis in an American eel, Anguilla rostrate. Chesapeake Sci. 18: $240-242$.

18. Oros, J., H. Lorenzo, M. Andrada, and J. Recuero. 2004. Type A-like retroviral particles in a metastatic intestinal adenocarcinoma in an emerald tree boa (Corallus caninus). Vet. Pathol. 41: 515-518.

19. Schmidt, G. D., and R. E. Kuntz. 1973. Nematode parasites of Oceanica. XX. Paraheterotyphlum ophiophagos n. sp. (Heterocheilidae), from the banded yellow-lip sea snake, Laticauda colubrina. Am. Midl. Nat. 89: 481484.

20. Shaw, C. E. 1962. Sea snakes at the San Diego Zoo. Int. Zoo Yearb. 4: 449-452.

21. Shetty, S., and R. Shine. 2002. Activity patterns of yellow-lipped sea kraits (Laticauda colubrina) on a Fijian Island. Copeia 1: 177-185.

22. Walker, I., B. Whitaker, and A. Kincaid. 1999. Lymphoid leukemia in a yellow-lipped sea krait, Laticauda colubrina: diagnosis and potential etiology. Proc. Int. Assoc. Aquat. Anim. Med. 30: 38-39.

Received for publication 19 January 2008 